\title{
Research on the Development of Circular Economy in Yulin Xiaowen Zhou ${ }^{\mathrm{a}^{*}}$ \\ ${ }^{1}$ School of Management, Yulin University, China, 719000 \\ a676969980@qq.com
}

Keywords: Circular economy; Yulin; Resources

\begin{abstract}
As a typical resource-based city, Yulin is a pilot city of economic cycle, but the cycle of economic developed slowly and there are some problems. The way to realize the rapid development of circular economy is increase recycling economy promotion, the establishment of technical support system, improve the incentive mechanism of circular economy, learning new technology in recycling of resources and so on.
\end{abstract}

\section{Introduction}

Yulin, Shaanxi Province, has always been stressed and pursued resource-dependent economic model, resulting in Yulin's abundant in natural resources but lagging far behind the resource-poor eastern coastal cities in economy, and its urban competitiveness is much lower than those of eastern and central cities of the same size. In recent years, the constant expansion of resource development, instead of making Yulin out of the underdeveloped plight, but widening the gap with the developed cities in the east, the relative competitiveness is increasingly weak.

\section{The State of Circular Economy Development in Yulin}

The circular economy of Yulin is still in its infancy, but in the field of industrial development of circular economy, has made some achievements, the development of circular economy in Yulin is mainly reflected in the following aspects:

The Basic Status of Circular Economy Strategic Position Established. As the circular economy pilot city in 2007, Yulin is the west east coal, the source of power transmission from west to East, west east gas pipeline, also one of the main areas of resource development at the same time, but also key areas of environmental protection. At the same time the rapid development of Yulin energy and chemical industry, to reach the standard after the treatment of pollutants emission, optimization City air environment, curb the deterioration of the ecological environment of the target.

Industrial Park circular Economy System Gradually Improved. The advantages of Yulin project using the allocation of resources, industrial layout according to the waste of resources, reduction, re-use of the principle, to extend the industrial chain, the basic form of coal - electricity fly ash - building materials industry, coal - coal tar chemical waste gas and coke powder recycling, coal, methanol and downstream products - - building materials food grade carbon dioxide, salt and caustic soda - PVC a chain of circular economy, circular economy industrial park system gradually improved.

The Benefits of Pilot Enterprises Circular Economy Show. With the continuing rise further the implementation of circular economy and energy price, many enterprises have to change the idea, From" Ask me to take part in the recycling economy" to "I want to recycling economy", has taken the initiative to increase capital investment, the use of advanced technology, wide implementation of circular economy projects, the city enterprises especially the economic benefits of recycling pilot enterprises has begun to appear. For example rich gas, using Yulin refinery waste heat power generation, saving 6536 degrees per hour, supporting the waste heat boiler and gas power plant installed capacity reached 9MW; acidic water allocation, can save 200000 tons of fresh water per year. Other enterprises should look off to build a closed chain of circular economy, make full use of resources. Get more revenue. 
Circular Economy Rapid Started in the Various Walks of Life. The implementation of water conservation and water planning system was executed, A number of sewage treatment plants have been built and put into operation, the formation of the sewage treatment capacity of 90 thousand tons per day. The county sewage treatment project is being implemented; Yulin, Shenmu, Jingbian vigorously promote central heating, reducing soot emissions; Yulin, Shenmu, Jingbian, Dingbian centralized gas supply, help to improve the atmospheric environment. City public transportation integrated optimization, strict management, add dual fuel taxi 360. Each department, each unit and carry out activities to create a conservation oriented agencies, formulate a series of measures to strengthen the management, saving expenses, clear responsibility, the construction of conservation oriented agencies included in the annual assessment.

\section{The Problems in the Development of Circular Economy in Yulin}

Lack Awareness of the Importance of Developing Circular Economy. The government leaders and the environmental protection departments and enterprises of YuLin continue to increase the understanding is not in place of importance to implement the development of circular economy. Because of the development of circular economy need to invest a lot of money to purchase import advanced technology and equipment, many enterprises do not have enough financial support, the main is no scientific concept of development of circular economy the pursuit of their own immediate interests, with sweeping the snow in front of the mentality of extensive economic development. The protection of the environment, still remain in the process only in emissions, not into the source control, fully recycling use of resources, to ensure full control of pollutant emissions last less concept. The government of Yulin is not enough to understand the trend and the trend of the domestic development of circular economy. For the masses, not saving awareness and awareness of environmental protection, the development of circular economy has nothing to do with themselves, that is The government is free to waste water and mineral resources.

Lack of Sound Policies and Support System. The circular economy is a technology economy needs to rely on advanced science and technology. If there is no strong high-tech as the support, will be equivalent to the house without a canopy, so in order to develop circular economy is an empty talk.[9] for now, Yulin city is completely developed by the coal resources, some level is still relatively backward. Lack of advanced technology, innovation ability, promote the development of circular economy system or 00 do not form a complete, sound technical support system. Also need to break the local characteristics, special technical problems of sewage treatment, low emissions of pollutants resource exploitation and environmental protection. At the same time, the corresponding policies and regulations are not perfect. The corresponding incentive and restrictive policy measures are not mature, energy saving, and adapt to the development of circular economy of water saving, equipment is not complete.

Resource Development and Utilization Efficiency Is too Low. As the development relies on coal resources for the city YuLin, There are many coal enterprises. But the enterprises only consider their own footprint size and mining cost and economic benefits, not to pay attention to conservation, efficient use of resources, the coal resources recovery rate is very low, the resources waste phenomenon is very serious, eat fat lost mining thick disposable thin thin, predatory exploitation of resources is very common. Even some coal enterprises regardless of mining exceeding the design capacity, fast water flow, accelerating mining. This and build a resource-saving society, the basic national policy of environmental friendly society and Scientific Outlook on Development is contrary.

Lack of Effective Incentive Mechanism. At present, The lack of effective incentive and restraint mechanisms, the lack of appropriate punishment or reward measures in YuLin. Resources property right is not clear, so that resources into public goods, free use of mining, causing serious damage to the ecological environment situation; experts believe that economic law is concerned, when the lost price signal will inevitably lead to the misuse of resources at the same time, waste recycling enterprises lack of effective compensation mechanism. The enterprise is not easy to obtain 
good economic benefits through the market, the effective use of resources, environmental protection and sustainable economic development goals can not rely on market mechanisms to complete; enterprises only consider their own economic benefits and costs, ecological environment is always trying to use free of charge, wanton discharge of waste, minimize the cost, the extensive use of resources, the exploitation of resources faster, more and more pollutants and waste emissions, Resources and ecological environment is becoming more and more serious, and the related policies of Taxation, reward and punishment are not perfect, which greatly restrict the enterprises to develop the circular economy actively.

\section{The Strategy of Optimizing Yulin Circular Economy}

In today's highly developed market economy, Yulin city should be fully aware of the necessity of the development of circular economy, which not only concerns the survival and development of an enterprise, but decided economic development throughout Yulin. Combining the current situation of the development of circular economy in Yulin city and the existing problems, put forward the corresponding strategies from two angles of government and enterprises respectively. In order to ensure economic stability and growth in the Yulin city of sustainable development.

The Government Should Increase Publicity and Supervision. The government departments should actively promote the recycling economy to carry out a wide range of knowledge, organization of circular economy promotion activities, to make the public aware of the benefits of the development of circular economy, promote relevant regulations and policies for the development of circular economy of advanced typical enterprises, waste of resources and exposure seeking profits, serious environmental pollution enterprises or individuals, society from all walks of life to improve circulation knowledge economy, clean production and sustainable development. At the same time, the government supervision

The Technical Support System for the Development of Circular Economy Should Be Established. The development of circular economy needs the advanced science and technology as the support, if there is no advanced technology input, the harmony of economic development and environment of circular economy in pursuit of the goal will be difficult to achieve fundamentally. Yulin municipal government can learn the related technology in Japan, high consumption of resources, traditional industries have low rate of comprehensive utilization of transformation and establish the high-tech industry capital and technology intensive, so as to improve economic efficiency, improve the living environment; learning the United States through government subsidies and tax incentives, encourage the development of circular economy enterprise technology. In short, the Yulin municipal government should take active measures to further increase investment in science and technology, research and development support the key technology of circular economy, such as deep processing of coal, coal oil and advanced technology. The implementation of incentive policies for technology development and to improve the scientific and technological innovator. The enthusiasm of the staff continue to carry out technical innovation. Improve the Yulin technical personnel to introduce incentive mechanism, technical personnel support technology of circular economy enterprise, transformation of scientific research, give some support and reward for the enterprise.

Improve the Incentive Mechanism of Developing Circular Economy. Yulin municipal government should formulate policies to promote the development of circular economy, perfect the corresponding incentive mechanism. For example, the use of advanced environmental protection technology and independent research and development of new technology enterprises, incentives, financial subsidies or tax reduction and exemption preferential policies; on the other hand, through taxes, fines and other economic means to be punished, so as to encourage enterprises to actively the development of circular economy. The economic policy provides a perfect incentive and restraint mechanism for the circular economy. The government can learn German green taxation policy is conducive to the government from the macro regulation and control the direction of the market, and urge enterprises to adopt advanced production technology of cleaner production, reduce the extent 
of damage to the environment, to use economic means to guide enterprises to achieve production the adjustment of the economic structure.

Enterprises Should Use the Resources Recycling. The enterprise should improve the ideological consciousness, fully aware of the importance of the development of circular economy for the long-term development of enterprise, not at the expense of the interests of future generations for the current profits, to actively promote the development of circular economy. In the exploitation of resources, to carry out long-term scientific planning, and strive to improve the level of resource exploitation; at the same time, the production process of the waste must be reasonable recycling, improve resource recovery rate. For example, the coal gangue is processed into bricks and cement, with the development of electric power industry coal slime, coal gangue, coal powder and cement wall, accelerators and other new building materials, but also pave the way for the use of coal gangue, filling coal mining subsidence area, turning waste into treasure.

Enterprises Should Actively Apply New Technology. The application of new technology enterprises can actively learn foreign advanced technology and environmental protection enterprises, can the company set up within the department specialized technical research and development, according to their actual situation, research and development for the enterprise resource utilization and environmental protection technology. For example, the use of advanced learning Shendong coal mining technology and intelligent equipment, not only helps to reduce the safety accidents, and reduce environmental pollution; the use of advanced environmental protection and clean production technology, can make the waste and waste water recycling, to maximize the recovery rate of resources, reduce the waste of resources.

\section{References}

[1] Wang Xirong etc. Research of the Development of Circular Economy in Yulin's Energy Chemical Base [J]. China Coal, 2014 (7):77-80(In Chian)

[2] Deng Ling etc. Research of the SWOT Analysis and Countermeasures of Xi'an's Urban Competitiveness [J].Journal of Xi'an University of Finance and Economics, 2014.4:266-269(In Chian)

[3] Yan Li. A Study of the Competitiveness Improvement of Coal Resource-based Cities in Shanxi Province [J]. Master's Thesis of North University of China, 2013(8):120-122(In Chian)

[4] Li Hongyan. Application of the SWOT Analysis in Urban Development Strategy [J]. Scientific Decision-Making, 2012 (10):188-191(In Chian)

[5] Shi Wei. A Study of the Issues of Circular Economy Development in Resource-based CitiesCase Study of Yulin [J]. Master's Thesis of Northwest University, 2013(9):101-103(In Chian)

[6] Li Dejiang etc. Analysis of the Improvement of Enterprises' Competitiveness in Resources-based Cities (Regions) in Hei Longjiang Province [J]. Business Research, 2014 (22) (In Chian)

[7] Ouyang Yanrong. Cultivation of Sustainable Competitiveness of Resource-based Cities- Case Study of Datong, Shanxi Province [J] Resource Development and Market, 2012 (22) :143 -146(In Chian)

[8] Zheng Chenghua. A Study of Countermeasures of Energy's Sustainable Development and Utilization in Yulin [J]. Market Modernization, 2013 (1) (In Chian)

[9] Yin Lijuan. Strategies to Avoid the "Resource Curse" Effect in Resource-rich Areas [J]. Science and Technology Management of Land and Resources, 2014 (2) (In Chian)

[10] Xie Zhenhua, Reflections on the Theory and Policy of Circular Economy [N]. Guangming Daily, 2013-11-3(In Chian) 